\title{
Embryological development of the human insula and its implications for the spread and resection of insular gliomas
}

\author{
"M. Yashar S. Kalani, M.D., Ph.D., ${ }^{1-4}$ Maziyar A. Kalani, B.S., ${ }^{1-3}$ \\ Ryder Gwinn, M.D., 5 Bart Keogh, M.D., 5 and Victor C. K. Tse, M.D., Ph.D. 3,6 \\ ${ }^{I}$ Institute for Stem Cell Biology and Regenerative Medicine, ${ }^{2}$ Institute for Neuro-Innovation and Translational \\ Neurosciences, and ${ }^{3}$ Department of Neurosurgery, Stanford University School of Medicine, Stanford, \\ California; ${ }^{4}$ Barrow Neurological Institute, Phoenix, Arizona; ${ }^{5}$ Swedish Neuroscience Institute, Seattle, \\ Washington; and ${ }^{6}$ Kaiser Neuroscience, Redwood City, California
}

\begin{abstract}
The human insular cortex, or the lobus insularis, is considered the developmentally most primitive lobe of the telencephalon. Covered by an overlying cortical lid, the insula has functions that are distinct from yet related to those of the adjacent temporal lobe and deep limbic structures. In the first part of this paper the authors outline the development of the human insula, including the cellular heterogeneity comprising the various parts of the insular lobe. Using the understanding gained from the development of the insula they then address implications of insular development for cortical development and connection as well as for tumorigenesis and tumor spread from the insula to other cortical structures, most notably the temporal lobe. An understanding of cortico-insular development and interconnection allows for both a better understanding of insular pathology and also facilitates planning of resection of cortico-insular gliomas to avoid damage to eloquent structures. (DOI: 10.3171/2009.5.FOCUS0997)
\end{abstract}

Key Words • insula • development • stem cell • glioma

$\mathrm{T}$ HE description of the insula is commonly credited to Johann C. Reil..$^{29}$ The insula is located at the base of the sylvian fissure on the lateral surface of the brain within the lateral sulcus. It is surrounded by the basal ganglia and hidden by the frontal, parietal, and temporal cortices. Given its position relative to other cortical structures, the insula has been described as an extension of the temporal lobe, a unique and phylogenetically ancient lobe of the telencephalon as well as a component of deeper limbic structures. Despite much discourse on the anatomy of the insula, little is known about its exact developmental course and its subsequent role in the development of other cortical areas.

In light of the insula's proximity and connection to much of the cerebrum, it is not surprising that tumors of the insula spread to adjacent cortical lobes with a noted clinical preference for the temporal lobe. Most reports indicate that the majority of insular gliomas are benign. ${ }^{14,22,35,37}$ Surgical treatment of glioma is challenging due to its infiltrative nature; within the insula, resection is particularly difficult owing to the proximity of critical structures such as the internal capsule and the middle cerebral artery and its branches. Most experts recommend

* Dr. M. Yashar S. Kalani and Maziyar A. Kalani contributed equally to this manuscript. biopsy with large dominant-hemisphere insular tumors so to avoid postoperative deficits. Unfortunately this is a suboptimal form of treatment for low-grade supratentorial gliomas in which extent of resection is independently associated with survival. ${ }^{21}$

An understanding of the embryological development of the insula will allow surgeons to better delineate anatomical landmarks and electrophysiologically monitor targets and tracts during surgery while minimizing risk of damage to eloquent structures. Furthermore, an understanding of the connections between the insula and adjacent structures will shed light on the mechanisms of tumorigenesis and spread of tumor in this region, allowing for development of better therapies.

\section{Developmental Anatomy of the Insula}

The insula is a paralimbic structure. During development, the insular cortex emerges from an allo- to isotype cortex. Studies on the development of the human cortex suggest that the insula is the first cortical structure to develop in the fetus. ${ }^{38}$ The process of cortical development begins in the 6th week of fetal life in an inferior cortical region. This region will later fold to become the limen insula. ${ }^{16,34}$ The telencephalic vesicles are developed from the anterior part of the prosencephalon. Through 


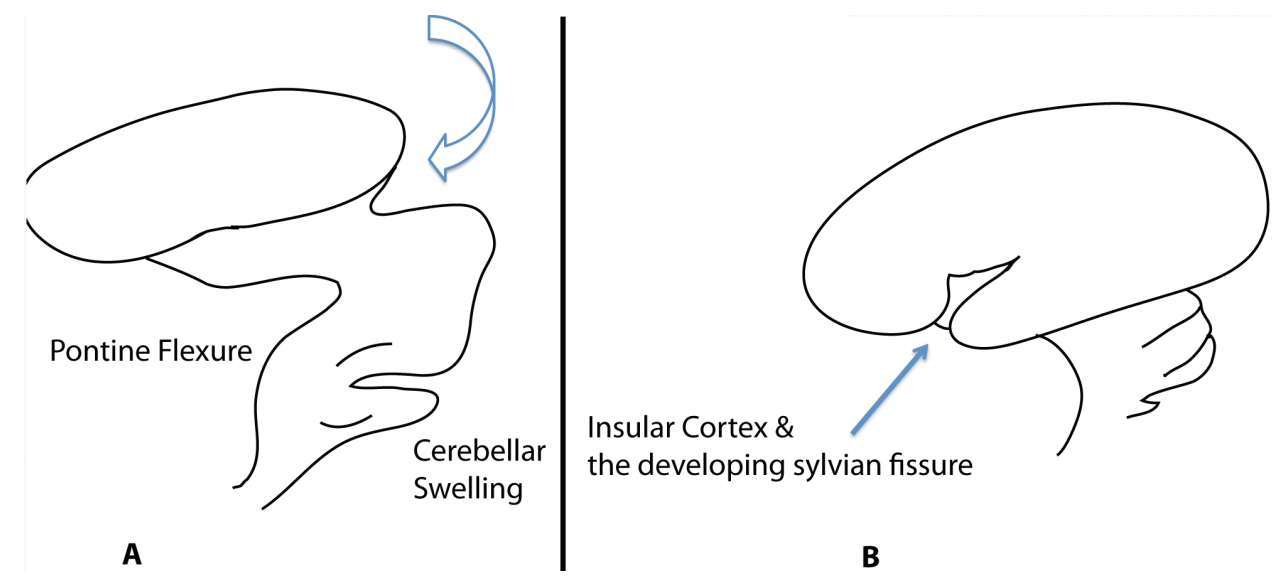

FIG. 1. Schematic representation of the development of the telencephalon. The rotation of the expanding telencephalon (dark blue arrow) pulls the archicortex, which is initially located at the medial wall of the ventricle toward the mesial temporal region. The fornix remains as the remnant of this connection.

the growth of the telencephalic vesicles, the primordial prosencephalon is pushed posteromedially and forms the diencephalon, where the optic vesicles arise. The junction of the telencephalon and diencephalon marks the future Monro foramen. Most of the diencephalon thus becomes the thalamus (alar plate) and globus pallidus (basal plate). The neocortex of the telencephalon develops disproportionately, resulting in a posteroinferior and outward movement of the cerebral hemisphere in a spiral resembling the horn of a ram (Fig. 1). The tip of this expansion is the temporal lobe. The central window of this spiral opens into the insula and within lies the remnant of the paleocortex and the archicortex, with its developing limbic and paralimbic structures. The window itself becomes the future sylvian fissure.

The expansion and rotation of the telencephalon in a posterior, lateral, and inferior manner occurs between the 14th and 16th week of gestation, with the concomitant appearance of the sylvian fissure at the 3rd and 4th month respectively. ${ }^{30,34}$ The earlier linear furrow on the surface of the lateral hemispheric region at the 13th week of gestation will become the posteroinferior periinsular sulcus at the 16th to 17th week of gestation. The sylvian fossa appears simultaneously with the periinsular sulci, forming a margined indentation at the 18th week of gestation. ${ }^{6,7}$ As cortical development further proceeds, the rotation and compaction of neural tissue buries the insula beneath the sylvian fissure, gradually covering it with the temporoparietal and then frontal lobes. ${ }^{7,9,11}$

Before the 16th week of gestation, the ganglionic hillock of the paleocortical mantle lies deep in the insula. This aggregation of cells lateral to the thalamus eventually undergoes lateral division and gives rise to the future caudate nucleus and putamen. Medial division of this aggregation of cells results in the formation of the amygdaloid body. The anterior ventral aspect of the paleocortex forms the septal nuclei. The archicortex, which sits on the medial dorsal surface of the telencephalic vesicle, forms the hippocampus and associated fornix. As the neocortex expands and the hemisphere rotates, the hippocampus is displaced toward the temporal lobe and leaves behind its fiber tract, the fornix, in the medial wall of the lateral ventricle. The fornix, connected to the mammillary body, is part of the paleocortex, and collectively they form the limbic system. The lateral wall of the developing ventricle is in effect the insula and is sometimes seen as the mesocortex - the cortex in transition between the archicortex and paleocortex. The process of cortical folding results in transposition of the insula and its burial while maintaining the connections formed during the initial development of the neural tube. The continued presence of the connecting fibers explains why the insula is so richly connected to nearby and remote centers within the fully developed brain. ${ }^{23}$

Upon completion of cortical folding, the insula can be separated into 2 unequal parts - the larger anterior and smaller posterior domains-by the central insular sulcus extending from the superior periinsular sulcus to the limen insula. ${ }^{36}$ The anterior insula consists of 3 short gyri, and the posterior insula consists of 2 long gyri. Additionally, the insula has accessory gyri with fiber connections to the orbitofrontal and lateral olfactory areas in its anteroinferior portion (Fig. 2). ${ }^{36}$

Three cytoarchitectonical areas have been described within the insular cortex of higher primates. ${ }^{24}$ These cellular divisions consist of 1) the trilayered anterior agranular area; 2) the pericentral nongranulated area; and 3) the posterior granular area. The cortical plate first becomes apparent at the insular region at around the 16th week of gestation. The telencephalic vesicle is initially composed of a layer of pseudostratified neuroepithelium, with the cell apices directed toward the ventricles. The basal membrane of these cells lies externally adjacent to the outer vascular connective tissue (the pial). During cell division, these neuroepithelial cells migrate toward the ventricles where they form the proliferative (matrix) zone. Here they undergo fate differentiation and develop into glia and neuroblasts. As the population of postmitotic neuroblasts increases in size so do the intermediate and the marginal zones. Eventually the marginal zone becomes the cortical plate where mature neurons and migrating neuroblasts reside. 

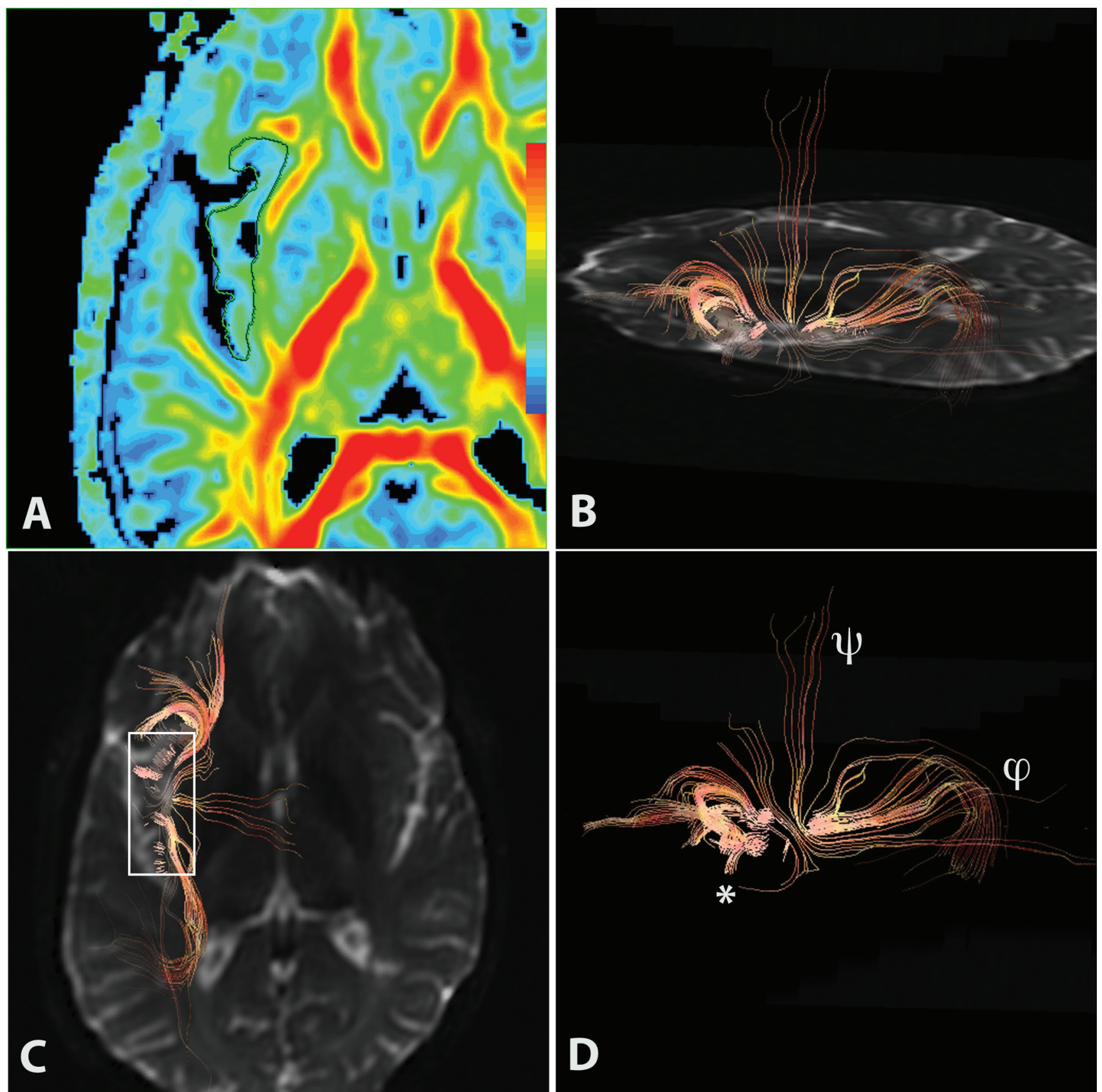

FIG. 2. Diffusion tensor imaging-based tractography of the insular cortex. These images were generated from an imaging study performed in a healthy volunteer, using a 3T GE HDx MR imaging scanner with an 8-channel head coil. The MR images were acquired using a single shot spin echo-echo planar sequence (bmax $1000 \mathrm{sec} / \mathrm{mm}^{2}$, TR $7800 \mathrm{msec}$, TE $88 \mathrm{msec}$, slice thickness $5 \mathrm{~mm}$ with a 1.5-mm gap between slices; matrix size $128 \times 128,24-\mathrm{cm}$ field of view, with both phase field of view and number of excitations set at 1.0). Twenty-five diffusion gradient directions were acquired. Calculated fiber tract projections were defined in both an antero- and a retrograde direction relative to the principal eigenvector in each voxel of the insula based upon the region of interest outlined in Panel A. Calculated fiber tracts of the insular cortex show clear connectivity between this area and medial temporal structures (including the amygdala) and subfrontal and posterior temporal cortices (Panels B, C, and D). These correspond to the uncinate fasciculus (indicated by asterisk), internal capsule fibers $(\psi)$ ), subfrontal tracts, amygdalar fibers, and the arcuate fasciculus $(\varphi)$ posteriorly. The rectangular box in Panel $\mathrm{C}$ indicates the approximate location of the insula, the focus of the tracts shown in Panel D.

The insula has many efferent and afferent projections to other adjacent and distant cortical regions ${ }^{23}$ (Fig. 2). The posterodorsal part of the insula connects with the retroinsular area, temporal cortex, supplementary mo- tor area, and the primary and secondary somatosensory cortices and specializes in auditory and motor movements. ${ }^{3,17}$ The anteroventral part connects with the entorhinal, cingulate, and periamygdaloid cortices and spe- 
cializes in olfactory, gustatory and viscero-autonomic functions. ${ }^{4,28,32}$ Currently there are no anatomically defined limits between the various cytoarchitectural divisions of the insula. Other proposed functions of the insula include modulation of language production and grammatical processing. ${ }^{12,15,20}$

\section{Functions of the Insula}

The literature abounds with descriptions of proposed or speculated functions of the insula; these include but are not limited to the processing of pain, anger, fear, disgust, happiness, and sadness, as well as conscious desires, such as in food craving and addiction. ${ }^{1,25}$ From primate and rodent studies it has been speculated that the insula serves as a center for the processing of convergent information and that it serves to produce an emotionally relevant context for sensory experiences. ${ }^{1}$ The insula, for example, receives information from afferent sensory pathways via the thalamus, integrates the various inputs, and sends efferent signals to other limbic structures such as the amygdala, the ventral striatum, and the orbitofrontal cortex. ${ }^{1}$ There are 2 primary functional divisions of the insula: anterior and posterior.

\section{Anterior Insula}

In addition to processing olfactory and gustatory inputs, the anterior insula is responsible for decoding information pertaining to body representation and subjective emotional experiences. ${ }^{8}$ The anterior insula of higher apes is unique in that it contains spindle neurons (also present in the anterior cingulate cortex) involved in processes such as empathy and self-awareness. ${ }^{26}$

\section{Posterior Insula}

The posterior insula receives input from the ventromedial nucleus of the thalamus and processes information pertaining to pain, temperature, and touch. ${ }^{5}$ The posterior insula may also be important for the perception of effort during exercise. ${ }^{39}$

\section{Connections to Adjacent Cortical Structures}

Using diffusion tensor imaging-based tractography and other methods such as dye tracing and enzymatic techniques, one can readily visualize the intricate network of afferent and efferent connections between the insula and cortical structures, including the frontal, parietal, cingulate, and temporal cortices (Fig. 2). Given the proximity and connections between the insular cortex and other neocortical areas, it is not surprising that insular tumors are frequently seen in association with other lobes.

Three notable domains of insular tumor extension are the temporal lobe, the frontal lobe, and the ventral striatum. A rich network of fibers connects the insula and the temporal lobe; insular efferents connect to the temporal pole and the supratemporal plane. ${ }^{1}$ Conversely, afferent fibers arising from the temporal pole, primary auditory, auditory association, and postauditory, superior temporal cortices, and the temporal operculum synapse onto the insula..$^{1,10,19}$ Insular tumors use fiber tracts passing through the inferior limiting or periinsular sulcus to spread to the temporal lobe. The insula has several key connections to the frontal lobes, including both afferent and efferent pathways to the motor area, prefrontal cortex, frontal operculum, and posterior and lateral orbital areas. The most notable of these pathways - the uncinate fasciculus (indicated by an asterisk in Fig. 2), the tracts migrating to the anterior limiting sulcus, and the subfrontal tracts-are used by low-grade insular tumors to spread to frontal areas. The third notable route of insular glioma spread is to the ventral striatum/septal region via the temporal stem. Interestingly, under normal physiological conditions, fibers from the insula connect to many structures adjacent to the ventral striatum, including the amygdala.

The landmark study by Yaşargil et al. ${ }^{43}$ has contributed greatly to our understanding of the surgical anatomy and the approaches to and methods for the resection of lowgrade insular tumors ${ }^{41}$ in addition to the pathophysiology and presentation ${ }^{42}$ of these tumors. Yaşargil stresses that limbic and paralimbic tumors have a greater affinity for more primitive areas than for neocortical structures. ${ }^{40-43}$ The abundance of afferent and efferent fibers emphasizes interactions between the insula and adjacent cortical structures, and may provide paths for the more selective spread of insular tumors to these regions (Fig. 2). These clinical observations underscore the embryonic relationship of the paleocortex and the archicortex with its developing limbic and paralimbic structures. The spread of the tumor has taken the same path as the migrating neuronal progenitors in the journey that they have taken during the course of embryonic development of the limbic and paralimbic structures.

\section{Cancer Stem Cell Hypothesis}

Overall, because the insula is anatomically situated in the center of the limbic and paralimbic areas, it is almost always involved by huge tumors irrespective of their origin. Many of the tumors in this region interestingly involve the temporal lobe and ventricular and subventricular regions involving the lobe. Adult neural stem cells have been shown to populate the subventricular $z_{0 n e^{18}}$ and the subgranular zone of the hippocampus. ${ }^{13,27}$ Within these germinating zones lie areas of neurogenesis.

The cancer stem cell theor $y^{31}$ for brain tumors was originally postulated by Cushing and Bailey. ${ }^{2}$ Recently Dirks and coworkers reported the isolation and characterization of a rare population of cells with stem cell-like properties within the mass of glioblastoma multiforme. ${ }^{33}$ The accumulation of mutations, translocations, deletions, and fusions is believed to give rise to neoplasms within this long-lived population of cells. The correlation between tumor location and established stem cell niches in the brain suggests that tumors of the insula may arise from cancer stem cells housed in adjacent niches in the brain in areas such as the hippocampus, ventricular zone, and subventricular zone and may use the aforementioned pathways for spread to adjacent structures. 


\section{Conclusions}

Insular tumors represent a challenging category of cerebral neoplasms: their predominantly low grade and benign course make them ideal candidates for total resection, while their intricate location and spread to key areas, including the temporal lobe, make them a surgical challenge. An anatomical and developmental understanding of the insula allows the surgeon to both plan a more accurate operative course and gain a better understanding of the route and mechanism of spread of these tumors to adjacent eloquent structures.

\section{Disclaimer}

The authors report no conflict of interest concerning the materials or methods used in this study or the findings specified in this paper.

\section{Acknowledgment}

Dr. M. Yashar S. Kalani is a fellow of the John W. Hanbery Neurosurgical Society.

\section{References}

1. Augustine JR: Circuitry and functional aspects of the insular lobe in primates including humans. Brain Res Brain Res Rev 22:229-244, 1996

2. Bailey PCH: A Classification of the Tumors of the Glioma Group on a Histogenetic Basis with a Correlated Study of Prognosis. Philadelphia: J. B. Lippincott, 1926

3. Bamiou DE, Musiek FE, Luxon LM: The insula (Island of Reil) and its role in auditory processing. Literature review. Brain Res Brain Res Rev 42:143-154, 2003

4. Brooks JC, Zambreanu L, Godinez A, Craig AD, Tracey I: Somatotopic organisation of the human insula to painful heat studied with high resolution functional imaging. Neuroimage 27:201-209, 2005

5. Chi JG, Dooling E, Gilles F: Gyral development of the human brain. Ann Neurol 1:86-93, 1977

6. Craig AD: How do you feel-now? The anterior insula and human awareness. Nat Rev Neurosci 10:59-70, 2009

7. Cunningham DJ: The development of the gyri and sulci on the surface of the island of Reil of the brain. J Anat Physiol 25:338-348, 1891

8. Damasio AR, Grabowski TJ, Bechara A, Damasio H, Ponto LL, Parvizi J, et al: Subcortical and cortical brain activity during the feeling of self-generated emotions. Nat Neurosci 3:1049-1056, 2000

9. Dorovini-Zis K, Dolman C: Gestational development of brain. Arch Pathol Lab Med 101:192-195, 1977

10. Emmans D, Markowitsch HJ, Guldin WO: AEV-insular axis: connectivity. Prog Brain Res 75:257-269, 1988

11. Feess-Higgins A, Larroche J-C: Le développement du cerveau foetal humain. Atlas Anatomique. Paris: Masson, 1987

12. Friederici AD, Bahlmann J, Heim S, Schubotz RI, Anwander A: The brain differentiates human and non-human grammars: functional localization and structural connectivity. Proc Natl Acad Sci U S A 103:2458-2463, 2006

13. Gould E, Reeves AJ, Graziano MS, Gross CG: Neurogenesis in the neocortex of adult primates. Science 286:548-552, 1999

14. Hadjipanayis CG, Kondziolka D, Flickinger JC, Lunsford LD: The role of stereotactic radiosurgery for low-grade astrocytomas. Neurosurg Focus 14(5):E15, 2003

15. Isnard J, Guenot M, Sindou M, Mauguiere F: Clinical mani- festations of insular lobe seizures: a stereo-electroencephalographic study. Epilepsia 45:1079-1090, 2004

16. Kodam S: Uber die sogenannten Basalganglien, Morphogenetische und pathologisch-anatomische Untersuchunger. Schweiz Arch Neurol Psychiatr 18:179-246, 1926 (Ger)

17. Lewis JW, Beauchamp MS, DeYoe EA: A comparison of visual and auditory motion processing in human cerebral cortex. Cereb Cortex 10:873-888, 2000

18. Luskin MB, Boone MS: Rate and pattern of migration of lineally-related olfactory bulb interneurons generated postnatally in the subventricular zone of the rat. Chem Senses 19:695-714, 1994

19. Markowitsch HJ, Emmans D, Irle E, Streicher M, Preilowski B: Cortical and subcortical afferent connections of the primate's temporal pole: a study of rhesus monkeys, squirrel monkeys, and marmosets. J Comp Neurol 242:425-458, 1985

20. McCarthy G, Blamire AM, Rothman DL, Gruetter R, Shulman RG: Echo-planar magnetic resonance imaging studies of frontal cortex activation during word generation in humans. Proc Natl Acad Sci U S A 90:4952-4956, 1993

21. McGirt MJ, Chaichana KL, Attenello FJ, Weingart JD, Than $\mathrm{K}$, Burger PC, et al: Extent of surgical resection is independently associated with survival in patients with hemispheric infiltrating low-grade gliomas. Neurosurgery 63:700-708, 2008

22. Mehrkens JH, Kreth FW, Muacevic A, Ostertag CB: Long term course of WHO grade II astrocytomas of the Insula of Reil after I-125 interstitial irradiation. J Neurol 251:14551464,2004

23. Mesulam MM, Mufson EJ: Insula of the old world monkey. I. Architectonics in the insulo-orbito-temporal component of the paralimbic brain. J Comp Neurol 212:1-22, 1982

24. Mesulam MM, Mufson EJ: The insula of Reil in man and monkey: architectonics, connectivity and function, in Peters A, Jones EG (eds): Cerebral Cortex. New York: Plenum Press, 1985, pp 179-226

25. Naqvi NH, Rudrauf D, Damasio H, Bechara A: Damage to the insula disrupts addiction to cigarette smoking. Science 315:531-534, 2007

26. Nimchinsky EA, Gilissen E, Allman JM, Perl DP, Erwin JM, Hof PR: A neuronal morphologic type unique to humans and great apes. Proc Natl Acad Sci U S A 96:5268-5273, 1999

27. Palmer TD, Takahashi J, Gage FH: The adult rat hippocampus contains primordial neural stem cells. Mol Cell Neurosci 8:389-404, 1997

28. Peyron R, Schneider F, Faillenot I, Convers P, Barral FG, Garcia-Larrea L, et al: An fMRI study of cortical representation of mechanical allodynia in patients with neuropathic pain. Neurology 63:1838-1846, 2004

29. Reil J: Untersuchungen über den Bau des grossen Gehirns im Menschen: Vierte Fortsetzung, VIII. Arch Physiol (Halle) 9:136-146, 1809

30. Retzius G: Das Menschenhirn: Studien in der makroskopischen Morphologie. Stockholm: Morstedt, 1896

31. Reya T, Morrison SJ, Clarke MF, Weissman IL: Stem cells, cancer, and cancer stem cells. Nature 414:105-111, 2001

32. Schreckenberger M, Siessmeier T, Viertmann A, Landvogt C, Buchholz HG, Rolke R, et al: The unpleasantness of tonic pain is encoded by the insular cortex. Neurology 64:1175-1183, 2005

33. Singh SK, Hawkins C, Clarke ID, Squire JA, Bayani J, Hide $\mathrm{T}$, et al: Identification of human brain tumour initiating cells. Nature 432:396-401, 2004

34. Streeter G: The development of the nervous system, in Keiblel FM (ed): Manual of Human Embryology, Vol II. Philadelphia: Lippincott, 1912

35. Talos IF, Zou KH, Ohno-Machado L, Bhagwat JG, Kikinis R, Black PM, et al: Supratentorial low-grade glioma resectability: statistical predictive analysis based on anatomic MR 
features and tumor characteristics. Radiology 239:506-513, 2006

36. Türe U, Yaşargil DC, Al-Mefty O, Yaşargil MG: Topographic anatomy of the insular region. J Neurosurg 90:720-733, 1999

37. Vanaclocha V, Saiz-Sapena N, Garcia-Casasola C: Surgical treatment of insular gliomas. Acta Neurochir (Wien) 139:1126-1135, 1997

38. Wai MS, Shi C, Kwong WH, Zhang L, Lam WP, Yew DT: Development of the human insular cortex: differentiation, proliferation, cell death, and appearance of 5HT-2A receptors. Histochem Cell Biol 130:1199-1204, 2008

39. Williamson JW, McColl R, Mathews D, Ginsburg M, Mitchell $\mathrm{JH}$ : Activation of the insular cortex is affected by the intensity of exercise. J Appl Physiol 87:1213-1219, 1999

40. Yaşargil M: Microneurosurgery, Vol 4. Stuttgart: Thieme, 1994
41. Yaşargil M, Krisht A, Türe U, Al-Mefty O, Yaşargil D: Microsurgery of insular gliomas: Part II: opening the sylvian fissure. Contemp Neurosurg 24:1-5, 2002

42. Yaşargil M, Krisht A, Türe U, Al-Mefty O, Yaşargil D: Microsurgery of insular gliomas: Part III: pathophysiology and clinical presentation. Contemp Neurosurg 24:1-6, 2002

43. Yaşargil M, Krisht A, Türe U, Al-Mefty O, Yaşargil D: Microsurgery of insular gliomas: Part I: surgical anatomy of the sylvian cistern. Contemp Neurosurg 24:1-8, 2002

Manuscript submitted April 8, 2009.

Accepted May 19, 2009.

Address correspondence to: Victor Tse, M.D., Ph.D., Stanford University School of Medicine, Department of Neurosurgery, 1201 Welch Road, MSLS P310, Stanford, California. email: tsevictor@ gmail.com. 